\title{
2011-2013 YILLARI ARASINDA DÜZENLENEN ULUSLARARASI TÜRK COĞRAFYASINDA UFRS SEMPOZYUMLARI ÜZERİNE BİR DEĞERLENDIRME
}

$* * *$

\author{
AN ASSESSMENT OF IFRS SYMPOSIUM IN THE TURKISH REGION \\ BETWEEN 2011-2013
}

\author{
Yrd. Doç. Dr. Cuma ERCAN \\ Kilis 7 Aralık Üniversitesi, İ̈BF, İşletme Bölümü \\ cercan27@gmail.com
}

\section{Öz}

Türkiye Finansal Raporlama Standartları (TFRS), 13 Ocak 2011 tarihinde yayınlanan ve 01 Temmuz 2012’de yürürlüğe giren 6102 sayılı Türk Ticaret Kanunu (TTK) çerçevesinde 01 Ocak 2013'de uygulanmaya başlamıştır. Bu sürece paralel olarak, ülkemizdeki uygulamalara yönelik hazırlık düzeyinin tespit edilip, çıkarımlara ulaşılması amacıyla 25-26 Ekim 2011 tarihlerinde Birinci Uluslararası Türk Coğrafyasında Uluslararası Finansal Raporlama Standartları (UFRS) Sempozyumu düzenlenmiştir. Daha sonra, geçiş sürecinin incelenip karşılaştırılabilir verilere ulaşılması amacı ile 16-17 Haziran 2012 tarihlerinde İkinci Uluslararası Türk Coğrafyasında UFRS Sempozyumu düzenlenmiştir. Son olarak, 2013 yılının ilk altı aylık uygulama sonuçlarını tartışmak ve öneriler geliştirmek amacıyla 07-08 Eylül 2013 tarihlerinde Üçüncü Uluslararası Türk Coğrafyasında UFRS Sempozyumu düzenlenmiştir. Türk Coğrafyasında, adını UFRS'den alan ve tamamen UFRS konularını kapsayan başka bir sempozyum bulunmamaktadır. Bundan dolayı bu sempozyumların Türkçe konuşulan ülkelerdeki UFRS uygulamalarında öncülük yapacağı beklenmektedir. Bu çalışmada, Uluslararası Türk Coğrafyası UFRS Sempozyumlarında sunulan bildiriler incelenerek, UFRS'ye olan katkılarının ortaya konulması amaçlanmıştır. Bu çerçevede sunulan bildirilerin sayısı, niteliği, odaklandığı standartlar, üniversitelere ve unvanlara göre dağılımı, ortak çalışmaların ağırlı̆̆ı ve araştırmacıların kullandıkları metodoloji gibi konular incelenmiştir. Buradan hareketle, sunulan bildirilerin yoğunluk alanı tespit edilerek, hangi konularda daha fazla yayın yapıldığı; hangi konularda eksikliklerin olduğu belirlenmiştir.

Anahtar Kelimeler: UFRS, TFRS, TMS.

Jel Kodları: M40, M41.

\begin{abstract}
Within the framework of the Turkish Commercial Law (TCL) no. 6102 which is published on January 13, 2011 and entered into force on 1 July 2012, The Turkish Financial Reporting Standards (TFRS) started to be implemented on January 1, 2013. Parallel to this process, the First International Turkish Geographical Symposium (IFRS) was organized on 25-26 October 2011 in order to determine the level of preparation for the applications in our country and to reach the conclusions. Then, the second International Turkish Geographical Symposium IFRS was held on 16-17 June 2012 with the aim of reviewing the transition period and reaching comparable data. Finally, the third IFRS Symposium was held not only to discuss the results of the application in the first six months of 2013 but also to improve the recommendations between 7-8 September 2013. There was no any other symposium convened in the Turkish Regions named International Financial Reporting Standards (IFRS) and no one covered the areas of IFRS issues. Therefore, it was expected that from the past symposia, Turkish-speaking countries would be pioneering the application of IFRS. In this study presented at the Turkish regions, International Symposium, we aim to examine the contributions made by the IFRS. In this context, the papers presented, their number and nature as well as focused standards were examined according to universities, professional titles, joint studies and research methodologies used. Consequently, we believe that it is possible to determine the density area of the papers that are presented, it has been determined which ones are lacking.
\end{abstract}

Keywords: IFRS, TFRS, TMS.

Jel Codes: M40, M41. 


\section{GİRIŞ}

Türkiye'de 1980'den sonra serbest piyasa ekonomisine geçilmesi ile birlikte, küreselleşme olgusu bütün alanlarda hissedilmeye başlanmıştır (İşseveroğlu vd. 2014:2). Bu süreç ile birlikte, finansal bilgilerin uluslararası düzeyde anlaşılması ve karşılaştırılması gündeme gelmiştir. Bu durum, finansal raporlamada uluslararası boyutta ortak bir dilin kullanılması gereğini ortaya çıkarmıştır. Bu ortak dil UFRS olarak kendini göstermiştir.

Avrupa Birliği 2005 yılında hisse senetleri borsalarda işlem gören işletmelere finansal tablolarını UFRS'ye uygun olarak hazırlama ve sunma zorunluluğu getirmiştir (Akdoğan, 2007:101). Ülkemizde de bu tarihten sonra bankalar ve borsada işlem gören şirketler finansal tablolarını UFRS'ye uyumlu olarak düzenlemeye başlamışlardır. 01 Temmuz 2012'de yürürlüğe giren 6102 sayılı TTK ile birlikte, TFRS'nin 01 Ocak 2013'de uygulanması zorunlu hale gelmiştir.

Bu gelişmelere paralel olarak, Ülkemizde UFRS ile ilgili birçok bilimsel çalışma ve toplantılar yapılmaktadır. Bunlardan birisi de MUMEYEK (Muhasebe-Finans Mesleki Yönetim, Eğitim ve Kültür) Vakfı tarafından her yıl gerçekleştirilen Türk Coğrafyasında UFRS Sempozyumlarıdır. Bu sempozyumların ilki, ülkemizdeki uygulamalara yönelik hazırlık düzeyinin tespit edilip, çıkarımlara ulaşılması amacıyla MUMEYEK Vakfı tarafından, 25-26 Ekim 2011 tarihleri arasında Sinop'ta düzenlenmiştir. İkincisi, geçiş sürecinin incelenip karşılaştırılabilir verilere ulaşılması amacı ile 1617 Haziran 2012 tarihlerinde Trabzon ilinde MUMEYEK Vakfı ile Trabzon SMMMO iş birliğiyle gerçekleştirilmiştir. Üçüncüsü ise, 2013 yılının ilk altı aylık uygulama sonuçlarını tartışmak ve öneriler geliştirmek amacıyla 07-08 Eylül 2013 tarihlerinde Balıkesir il merkezinde MUMEYEK Vakfı ve Balıkesir SMMMO'nun paydaşlığı ile yapılmıştır (http://sempozyum.mumeyek.org/).

$\mathrm{Bu}$ çalışmada, 2011-2013 yılları arasında Uluslararası Türk Coğrafyasında UFRS Sempozyumları'nda sunulan bildiriler incelenerek, UFRS'ye olan katkılarının ortaya konulması amaçlanmıştır.

\section{LITERATÜR}

Türkiye'de muhasebe alanında yapılmış literatür incelenmesi şeklindeki çalışmaların sayısı az olmakla birlikte, son yıllarda bu tür çalışmaların sayısında bir artış eğilimi gözlenmektedir. Bu çalışmaların bazılarını şöyle sıralayabiliriz:

İşseveroğlu, Ercan ve Aracı (2014), “Türkiye'de 2005-2013 Yılları Arasında UFRS Konusunda Yapılan Akademik Çalışmalara İlişkin Bir Araştırma” yapmışlar. Bu çalışmada 2005-2013 yılları arasında TFRS, TMS ve KOBİ TFRS konularında yapılmış olan makale ve bildirilerin profili ve katkısının ortaya konulması amaçlamışlar. Makalelerin \%39'u TFRS, \%54'ü TMS, \%7'si ise KOBİ TFRS konulariyla ilgiliyken, bildirilerin \%50,9'u TFRS, \%35,2'si TMS, \%13,9'u ise KOBİ TFRS ile ilgili olduğu görülmüştür.

Alkan (2014), “Türkiye'de Muhasebe Alanında Yapılan Lisansüstü Tez Çalışmaları Üzerine Bir Araştırma" yapmıştır. Alkan bu çalışmada 1984-2012 yılları arasında muhasebe alanında yazılan ve erişime açık 656 lisansüstü tezlerin; profilini, alana katkılarını, içerik ve konu açısından zaman içindeki yönelimini incelemiştir.

Yine Alkan (2013), “Araştırmacıların UFRS Alanına Bilimsel Katkıları: UFRS Konusunda Yapılan Lisans Üstü Tezlere İlişkin Bir Araştırma" gerçekleştirmiştir. Araştırma sonunda tezlerin TMS 12 Ertelenmiş Vergi Uygulamaları ve TMS 23 Borçlanma Maliyetleri konularında yoğunlaştı̆g 1 görülmektedir.

Önce ve Başar (2010), “Türkiye'deki Akademik Araştırma Dergilerinde Muhasebe Alanında Yazılmış Makalelerin Analizi” ile ilgili bir çalışma yapmışlar. Bu çalışmaya göre, 2000-2008 yılları 
arasında en fazla makalenin Finansal Muhasebe, Maliyet ve Yönetim Muhasebesi ile Muhasebe Standartları kategorilerinde yazıldığı saptanmıştır.

Yereli ve diğerleri (2010), "Uluslararası Muhasebe Eğitimi Literatüründen Bir Kesit: 19972008 Dönemi" ile ilgili bir araştırma gerçekleştirmişler. Araştırmada 1997-2008 döneminde uluslararası dergilerde muhasebe eğitimi ile ilgili makalelerin literatür taramasını yapılmış ve bu kapsamda toplam 789 adet makale incelenmiştir.

Dinç, Çankaya ve Kaya (2009), “Türkiye’de Muhasebe Eğitimi Literatürünün İncelemesi” ile ilgili bir çalışma yapmışlar. Bu çalışmada 1998-2008 yılları arasında Türkiye' de yayınlanmakta olan muhasebeyle ilgili 52 farklı akademik dergide yayınlanmış muhasebe eğitimi ile doğrudan ilişkili 74 makale konu, nitelik, esas alınan kitle vb. kriterler dikkate alınarak incelenmiştir. Çalışma sonucuna göre etik, değişime uyum, üniversite sanayi iş birliği, öğretim yöntemi gibi konuların daha az işlendiği ortaya çıkmıştır.

Uysal (2009), "Muhasebe ve Bilim Dünyası Dergisinde 2004-2006 Yıllarında Çıkan Muhasebe Araştırmalarının Bibliyometrik Analizi” üzerine bir çalışma yapmıştır. Uysal bu çalışmada Muhasebe ve Bilim Dünyası dergisinde 2004-2006 yılları arasında çıkan muhasebe araştırmalarına yönelik atıf analizi yapmıştır.

Selimoğlu ve Uzay (2007), “Türkiye'de Denetim Alanında Yapılan Çalışmaların İçerik Analizi” ile ilgili bir çalışma yapmışlar. Bu çalışmada, 1995-2006 döneminde yayınlanan bağımsız denetimle ilgili makale ve bildirileri incelemişlerdir. Çalışma sonunda, denetime olan ilgisinin yıllar itibariyle artmakta olduğu ve özellikle finansal skandalların yaşandığı 2002 ve 2003 yıllarında en üst düzeye çıktığı tespit edilmiştir.

Sakin (2008), 1972-2007 tarihleri arasında yayımlanmış olan muhasebe ve finans makalelerini incelemiştir. Yapılan bu çalışmada, finans ve muhasebe makalelerinin nitel ve nicel karakteristiklerine ilişkin genel değerlendirmeler yapılması amaçlanmıştır.

Gücenme (2006), “1979-2005 Yılları Arasında Düzenlenen Türkiye Muhasebe Eğitim Sempozyumları Üzerine Bir Değerlendirme” yapmıştır. Bu dönemde toplam yirmi dört sempozyum yapılmıştır. Sempozyum konularının değişen ekonomik koşullara uyum sağlama çabası içindeki muhasebe eğitiminin gündemini izleyebildiğini söylemek mümkündür. İlk yıllarda muhasebe eğitiminin mevcut durumu ve eksik yönleri yabancı ülkelerle karşılaştırmalı olarak ele alınıp incelenirken, son yıllarda küreselleşmenin gerektirdiği uluslararası entegrasyona dayalı konuların ele alındığg görülmektedir.

\section{ARASTTIRMANIN METODOLOJISİ}

Araştırmada 2011-2013 yılları arasında yapılan Uluslararası Türk Coğrafyasında UFRS Sempozyumları'nda kabul edilen bildiriler incelenmiştir. Kabul edilen bildirilerin tam metnine elektronik ortamda yayınlanan "WORLD OF IFRS" dergisinin "Dergi Arşivi” bölümünde ulaşılmaktadır (http://dergi.mumeyek.org/arsivler.php).

Buradan bildiriler tek tek incelenerek, ilgili olduğu standart tespit edilmiştir. Veri analizinde kategorik veri analizi tekniklerinden içerik analizi kullanılmıştır.

Sosyal bilimlerde sıkça kullanılan bir yöntem olan içerik analizi, yazılı materyallerin sistematik bir şekilde incelenmesine olanak sağlamaktadır. İçerik analizinde veriler düzenlenerek kodlanır, temalar belirlenir ve elde edilen bulgular değerlendirilir (Alkan, 2014: 44). 
Araştırmada bildiriler; sayıları, ortak çalışmaların ağırlığı, çalışmaların odaklandığı standartlar, üniversiteler arasındaki paylaşımı ve araştırmacıların kullandıkları metodoloji gibi konular çerçevesinde incelenmiştir.

\section{ARAŞTIRMANIN BULGULARI}

Araştırma kapsamında toplam 91 bildiri incelenmiştir. Bu bildirilerin sempozyumlar arasındaki dağılımı Tablo 1'de verilmiştir. Tablo 1'de görüldüğü gibi, Birinci Uluslararası Türk Coğrafyası UFRS Sempozyumu'nda 20, İkinci Uluslararası Türk Coğrafyası UFRS Sempozyumu'nda 38, Üçüncü Uluslararası Türk Coğrafyası UFRS Sempozyumu'nda 33 bildiri sunulmuştur.

Tablo 1: Bildirilerin Sempozyumlar Arasındaki Dağılımı

\begin{tabular}{|l|c|c|}
\hline Sempozyumlar & Sayı & Yüzde \\
\hline 1.Uluslararası Türk Coğrafyasında UFRS Sempozyumu & 20 & 21,98 \\
\hline 2.Uluslararası Türk Coğrafyasında UFRS Sempozyumu & 38 & 41,76 \\
\hline 3.Uluslararası Türk Coğrafyasında UFRS Sempozyumu & 33 & 36,26 \\
\hline TOPLAM & 91 & 100 \\
\hline
\end{tabular}

Sempozyumlarda sunulan bildirilerin niteliklerine göre dağılımı incelenmiş ve Tablo 2'de gösterilmiştir. Tablo 2'de görüldüğü gibi araştırma kapsamında incelenen bildirilerin, \%48,36's1 teorik, \%31,77'si ampirik ve \%19,78'i uygulama çalışmalardan oluşmaktadır.

Tablo 2: Bildirilerin Niteliklerine Göre Dağılımı

\begin{tabular}{|l|c|c|c|c|c|}
\hline Konular & 1.Sempozyum & 2.Sempozyum & 3.Sempozyum & Toplam & Yüzde \\
\hline Teorik & 9 & 21 & 14 & 44 & 48,36 \\
\hline Amprik & 8 & 12 & 9 & 29 & 31,77 \\
\hline Uygulama & 3 & 5 & 10 & 18 & 19,78 \\
\hline Toplam & 20 & 38 & 33 & 91 & 100 \\
\hline
\end{tabular}

Bildirilerin konulara göre dağılımı Tablo 3 'te verilmiştir. Tablo 3 incelendiğinde, bildirilerin sırasıyla, Meslek mensuplarının TMS/TFRS ile ilgili farkındalığı $(\% 14,29)$, KOBİ TFRS $(\% 9,89)$, Denetim $(\% 9,89)$, UFRS'ye geçiş Süreci/Sorunlar $(\% 7,70)$, Yeni TTK $(\% 5,49)$ konularına odaklandığı görülmektedir. Diğer $(\% 6,59)$ başlığı altında yer alan bildiriler genellikle Azerbaycanlı akademisyenlerce yazılmış ve UFRS kapsamı dışında kalan konulardır.

Tablo 3. Bildirilerin Konulara Göre Dağılımı

\begin{tabular}{|l|c|c|c|c|c|}
\hline Konular(Standartlar) & 1.Sem. & 2.Sem. & 3.Sem. & Toplam & Yüzde \\
\hline TMS/TFRS Algılama Düzeyi/Farkındalık & 5 & 4 & 4 & 13 & 14,29 \\
\hline TMS 1 Finansal Tabloların Sunuluşu & & 1 & & 1 & 1,10 \\
\hline TMS 2 Stoklar & & 2 & 1 & 3 & 3,30 \\
\hline TMS 7 Nakit Akış Tabloları & & 1 & 1 & 2 & 2,19 \\
\hline TMS 8 Muh. Pol. M. Tah. Değ. Ve Hatalar & & & 1 & 1 & 1.10 \\
\hline TMS 10 Raporlama Dön. Sonrası Olaylar & & & 1 & 1 & 1,10 \\
\hline TMS 11 İnşaat Sözleşmeleri & 1 & & & 1 & 1,10 \\
\hline TMS 16 Maddi Duran Varlıklar & & 2 & & 2 & 2,19 \\
\hline TMS 18 Hasılat & & & 1 & 1 & 1,10 \\
\hline
\end{tabular}




\begin{tabular}{|l|c|c|c|c|c|}
\hline TMS 19 Çalışanlara Sağlanan Faydalar & & 1 & & 1 & 1,10 \\
\hline TMS 23 Borçlanma Maliyetleri & & & 1 & 1 & 1,10 \\
\hline TMS 33 Hisse Başına Kazanç & 1 & 2 & & 3 & 3,30 \\
\hline TMS 36 Varlıklarda Değer Düşüklüğü & 1 & 1 & 1 & 3 & 3,30 \\
\hline TMS 38 Maddi Olmayan Duran Varlıklar & & 2 & & 2 & 2,19 \\
\hline TMS 40 Yatırım Amaçlı Gayrimenkuller & & & 1 & 1 & 1,10 \\
\hline TMS 41 Tarımsal Faaliyetler & & 1 & 2 & 3 & 3,30 \\
\hline TFRS 1 TFRS'nin İlk Uygulamas1 & 1 & & & 1 & 1,10 \\
\hline KOBİ TFRS & 2 & 6 & 1 & 9 & 9,89 \\
\hline Denetim & 4 & 2 & 3 & 9 & 9,89 \\
\hline Yeni TTK & & 2 & 3 & 5 & 5,49 \\
\hline Muhasebe Eğitimi & 1 & 2 & & 3 & 3,30 \\
\hline F. Raporlama Yolsuzlukları & & 2 & 1 & 3 & 3,30 \\
\hline UFRS/Finansal Analiz/SPK & & 2 & 1 & 3 & 3,30 \\
\hline Değerleme & & 1 & 1 & 2 & 2,19 \\
\hline Araştırmaların UFRS'ye Bilimsel Katkılar1 & & & 1 & 1 & 1,10 \\
\hline UFRS-Kurumsal Şeffaflık & & & 1 & 1 & 1,10 \\
\hline TFRS'nin Yabanc1 Yatırımcılar Üz. Etkisi & & 1 & 1 & 2 & 2,19 \\
\hline UFRS'ye geçiş Süreci / Sorunlar & 4 & 2 & 1 & 7 & 7,70 \\
\hline Diğer & & 1 & 5 & 6 & 6,59 \\
\hline TOPLAM & 20 & 38 & 33 & 91 & 100 \\
\hline
\end{tabular}

Sempozyumlarda sunulan bildirilerin yazar sayısına göre dağılımı Tablo 4'de verilmiştir. Tablo 4'de de görüldüğü gibi çalışmaların \%40,66'sı tek yazarlı, \%41,76's1 iki yazarlı, \%15,38'i üç yazarlıdır. Bu sonuçlara göre en çok çalışma ikili olarak yapılmıştır. Diğer taraftan, bildirilerden birisi 5 , diğeri ise 9 yazarlıdır. Bu iki bildiri de ön lisans ve lisans öğrencileri tarafından hazırlanmıştır.

Tablo 4: Bildirilerin Yazar Sayısına Göre Dağılımı

\begin{tabular}{|c|c|c|c|c|c|}
\hline Yazar Sayısı & 1.Sempozyum & 2.Sempozyum & 3.Sempozyum & Toplam & Yüzde \\
\hline 1 & 7 & 15 & 15 & 37 & 40,66 \\
\hline 2 & 9 & 13 & 16 & 38 & 41,76 \\
\hline 3 & 4 & 8 & 2 & 14 & 15,38 \\
\hline 4 ve üstü & - & 2 & - & 2 & 2,20 \\
\hline Toplam & 20 & 38 & 33 & 91 & 100 \\
\hline
\end{tabular}

Sempozyumlarda sunulan bildirilerin unvanlara göre dağılımı incelenmiştir. Tablo 5 'te görüldüğ̈̈ gibi 91 bildiri, farklı unvanlara sahip toplam 169 yazar tarafından hazırlanmıștır. Bunların \%8,29'u Profesör, \%13,01'i Doçent, \%25,46's1 Yardımc1 Doçent, \%11,24'ü Doktor, \%11,24'ü Öğretim Görevlisi, \%11,24'ü Araştırma Görevlisi, \%6,51'i Yüksek lisans ve Doktora Öğrencileri, $\% 13,01$ 'i ise diğer unvanlara sahip yazarlar tarafından hazırlanmıştır. Diğer grup, SMMM, YMM, Ön lisans ve Lisans öğrencileri ile farklı unvanlarla kamu kurumlarında çalışan kişilerden oluşmaktadır. $\mathrm{Bu}$ sonuçlara göre en çok Yardımcı Doçentlerin çalışmalarda yer aldıkları görülmektedir. Yardımcı Doçentleri, Doçentler ve diğer grup izlemektedir. 
Tablo 5: Çalışmaların Unvanlara Göre Dağılımı

\begin{tabular}{|l|c|c|c|c|c|c|}
\hline $\begin{array}{l}\text { Yazarların } \\
\text { Unvanları }\end{array}$ & $\begin{array}{c}\text { Tekli } \\
\text { Çalışma }\end{array}$ & $\begin{array}{c}\text { İkili } \\
\text { Çalışma }\end{array}$ & $\begin{array}{c}\text { Üçlü } \\
\text { Çalışma }\end{array}$ & $\begin{array}{c}\text { Dört ve } \\
\text { Üstü }\end{array}$ & Toplam & Yüzde \\
\hline Prof. Dr. & - & 9 & 5 & - & 14 & 8,29 \\
\hline Doç. Dr. & 5 & 14 & 3 & - & 22 & 13,01 \\
\hline Yrd. Doç. & 13 & 17 & 11 & 2 & 43 & 25,46 \\
\hline Dr. & 7 & 6 & 6 & - & 19 & 11,24 \\
\hline Öğr. Gör. & 1 & 11 & 5 & 2 & 19 & 11,24 \\
\hline Arş. Gör. & 4 & 9 & 6 & - & 19 & 11,24 \\
\hline Öğrenci & 4 & 4 & 3 & - & 11 & 6,51 \\
\hline Diğer & 3 & 6 & 3 & 10 & 22 & 13,01 \\
\hline Toplam & 37 & 76 & 42 & 14 & 169 & 100 \\
\hline
\end{tabular}

Yazarların bağı oldukları üniversiteleri belirlemek amacıyla Tablo 6 oluşturulmuştur. Buna göre, 79 bildiri Türkiye'deki üniversitelerin akademisyenlerince hazırlanırken, 12 bildiri yurtdışındaki üniversitelerin akademisyenlerince hazırlanmıştır. Tablo 6'da görüldüğü gibi, yurtiçinde en çok çalışmanın Bilecik Şeyh Edebali Üniversitesi'nce yapıldığı görülmektedir. Bunu sırasıyla diğer grup (SMM, YMM ve Farklı kurumlarda çalışan kişiler), Dokuz Eylül Üniversitesi, Trakya Üniversitesi, Balıkesir Üniversitesi, Sakarya Üniversitesi izlemektedir. Burada dikkat çeken bir konu, Trakya Üniversitesi yayınlarının tamamının yüksek lisan öğrencisi tarafından hazırlanmasıdır. Diğer bir konu ise, yurtdışındaki yayınların tamamının Azerbaycanlı yazarlar tarafindan hazırlanmasıdır.

Tablo 6: Yazarların Bağlı Olduğu Üniversitelere Göre Dağılım

\begin{tabular}{|l|c|l|c|}
\hline Üniversiteler & Sayı & Üniversiteler & Sayı \\
\hline Bilecik Şeyh Edebali Üniversitesi & 7,33 & Süleyman şah Üniversitesi & 1 \\
\hline Dokuz Eylül Üniversitesi & 5,83 & İstanbul Aydın Üniversitesi & 1 \\
\hline Trakya Üniversitesi & 5 & Haliç Üniversitesi & 1 \\
\hline Balıkesir Üniversitesi & 4,50 & Erciyes Üniversitesi & 0,50 \\
\hline Sakarya Üniversitesi & 4,71 & Anadolu Üniversitesi & 0,50 \\
\hline Karadeniz Teknik Üniversitesi & 3,50 & İstanbul Tic. Üniversitesi & 0,50 \\
\hline Okan Üniversitesi & 3,50 & Amasya Üniversitesi & 0,50 \\
\hline Celal Bayar Üniversitesi & 3 & Yalova Üniversitesi & 0,50 \\
\hline Bülent Ecevit Üniversitesi & 2,66 & Osmaniye Korkut Ata Ün. & 0,50 \\
\hline Selçuk Üniversitesi & 2,50 & Kilis 7 Aralık Üniversitesi & 0,50 \\
\hline Hakkâri Üniversitesi & 2,50 & K. Maraş Sütçü İmam Ün. & 0,50 \\
\hline Kırklareli Üniversitesi & 2 & Gaziantep Üniversitesi & 0,50 \\
\hline Çankırı Karatekin Üniversitesi & 2 & Cumhuriyet Üniversitesi & 0,50 \\
\hline İnönü Üniversitesi & 1,66 & Afyon Kocatepe Üniversitesi & 0,33 \\
\hline Ondokuz Mayıs Üniversitesi & 1,50 & Bozok Üniversitesi & 0,33 \\
\hline Muğla Üniversitesi & 1,50 & Uşak Üniversitesi & 0,33 \\
\hline Niğde Üniversitesi & 1 & Pamukkale Üniversitesi & 0,33 \\
\hline Ege Üniversitesi & 1 & Şırnak Üniversitesi & 0,33 \\
\hline R. Tayip Erdoğan Üniversitesi & 1 & Azerbaycan Devlet Ziraat Üni. & 1 \\
\hline Ordu Üniversitesi & 1 & Azerbaycan Devlet İktisat Üni. & 1 \\
\hline
\end{tabular}




\begin{tabular}{|l|c|l|c|}
\hline Sinop Üniversitesi & 1 & Azerbaycan Devlet Tarım Ünivers. & 7 \\
\hline Erzincan Üniversitesi & 1 & Azerbaycan Kolej Direktörü & 1 \\
\hline Düzce Üniversitesi & 1 & Azerbaycan Kredi İt.Böl. & 1 \\
\hline İstanbul Kavram & 1 & Azerbaycan Unibank & 1 \\
\hline Maltepe Üniversitesi & 1 & Diğer & 6,66 \\
\hline Toplam & & & 91 \\
\hline
\end{tabular}

\section{SONUÇ}

Küreselleşmenin bir sonucu olarak, Uluslararası Finansal Raporlama Standartları ülkemizde de uygulanmaya başlamıştır. $\mathrm{Bu}$ sürece paralel olarak, MUMEYEK Vakfı tarafından 2011 yılında başlamak üzere her yıl "Türk Coğrafyasında UFRS Sempozyumu” gerçekleştirilmektedir. Bu çalışmaların Türkçe konuşulan ülkelerde UFRS uygulamalarında öncülük yapacağı beklenmektedir.

Bu nedenle, MUMEYEK Vakfi tarafindan gerçekleştirilen bu sempozyumların UFRS'ye olan katkılarını ortaya koymak amacıyla bu çalışma yapılmıştır. Araştırmada 2011-2013 yılları arasında yapılan Uluslararası Türk Coğrafyasında UFRS Sempozyumlarında kabul edilen bildiriler incelenmiştir.

Araştırma kapsamında toplam 91 bildiri incelenmiştir. Araştırma kapsamında incelenen bildirilerin, \%48,36's teorik, \%31,77'si ampirik ve \%19,78'i uygulama çalışmalardan oluşmaktadır. Sempozyum kapsamında sunulan bildirilerin sirasıyla, Meslek mensuplarının TMS/TFRS ile ilgili farkındalığı $(\% 14,29)$, KOBİ TFRS $(\% 9,89)$, Denetim $(\% 9,89)$, UFRS'ye geçiş Süreci / Sorunlar $(\% 7,70)$, Yeni TTK $(\% 5,49)$ konularına odaklandığı görülmektedir.

Sempozyumlarda sunulan bildirilerin \%40,66'sı tek yazarlı, \%41,76'sı iki yazarlı, \%15,38'i üç yazarlıdır. Bu sonuçlara göre en çok çalışma ikili olarak yapılmıştır. Bu bildiriler, farklı unvanlara sahip toplam 169 yazar tarafından hazırlanmıştır. Bunların \%8,29'u Profesör, \%13,01'i Doçent, \%25,46's1 Yardımc1 Doçent, \%11,24'ü Doktor, \%11,24'ü Öğretim Görevlisi, \%11,24'ü Araştırma Görevlisi, \%6,51'i Y üksek lisans ve Doktora Öğrencileri, \%13,01'i ise diğer unvanlara sahip yazarlar tarafından hazırlanmıştır. Bu sonuçlara göre en çok Yardımcı Doçentlerin çalışmalarda yer aldıkları görülmektedir.

Sunulan bildirilerin 79'u Türkiye'deki üniversitelerin akademisyenlerince hazırlanırken, 12'si yurtdışındaki üniversitelerin akademisyenlerince hazırlanmıştır. Yurtiçinde en çok çalışmanın Bilecik Şeyh Edebali Üniversitesi'nce yapıldığı görülmektedir. Bunu sırasıyla diğer grup (SMM, YMM ve Farklı kurumlarda çalışan kişiler), Dokuz Eylül Üniversitesi, Trakya Üniversitesi, Balıkesir Üniversitesi ve Sakarya Üniversitesi izlemektedir.

\section{KAYNAKLAR}

AKDOĞAN, N. (2007). “Türkiye Muhasebe/Finansal Raporlama Standartlarının Uygulanma Süreci: Sorunlar Çözüm Önerileri”. Mali Çözüm Dergisi, s.80.

ALKAN, G. (2014). “Türkiye’de Muhasebe Alanında Yapılan Lisansüstü Tez Çalışmaları Üzerine Bir Araştırma (1984-2012)”. Muhasebe ve Finansman Dergisi, s.611, s.41-52.

ALKAN, G. (2013). “Araştırmacıların UFRS Alanına Bilimsel Katkıları: UFRS Konusunda Yapılan Lisans Üstü Tezlere İlişkin Bir Araştırma”, Türk Coğrafyasında UFRS Sempozyumu, Balıkesir. 
DİNÇ, E., ÇANKAYA, F. ve KAYA, U. (2009). “Türkiye'de Muhasebe Eğitimi Literatürünün İncelenmesi (1998-2008)". 28. Türkiye Muhasebe Eğitimi Sempozyumu, 20-24 Mayıs 2009 Alaçatı-Çeşme. ss.201-229.

GÜCENME, Ü. (2006). “1979-2005 Yılları Arasında Düzenlenen Türkiye Muhasebe Eğitim Sempozyumları Üzerine Bir Değerlendirme”. Muhasebe ve Finansman Dergisi, s.31, s.33-40.

İŞSEVEROĞLU, G., ERCAN, C. ve ARACI, H. (2014). "Türkiye'de 2005-2013 Yılları Arasında UFRS Konusunda Yapılan Akademik Çalışmalara İlişkin Bir Araştırma”. 2.Uluslararars1 Muhasebe ve Finans Sempozyumu, 29-31 Mayıs, Bursa.

SAKİN, T. (2008). "A Content Analysis of Papers Published in Journal of The School of Business Administration: Accounting and Finance (1972-2007)". İ.Ü. İşletme Fakültesi Dergisi, 37(1):13-21.

SELIMOĞLU, K. S. ve UZAY, Ş. (2007). “Türkiye'de Son 10 Yılda Bağımsız Denetim Alanında Yapılan Araştırmalar: Literatür Taraması” Mali Çözüm İSMMMO Yayın Organı, s.39.

ÖNCE, S. ve BAŞAR, B. (2010). “Türkiye'deki Akademik Araştırma Dergilerinde Muhasebe Alanında Yazılmış Makalelerin Analizi:(2000-2008)”, Muhasebe ve Finansman Dergisi, s.45, s.55-68.

UYSAL, Ö. (2009). "Muhasebe ve Bilim Dünyası Dergisinde 2004-2006 Yıllarında Çıkan Muhasebe Araştırmalarının Bibliyometrik Analizi”, XXVIII. Muhasebe Eğitimi Sempozyumu, s.181-198.

YERELİ, A. N., KAYALI, C., ÖZDOĞAN, B., GACAR, A. ve İZMİRLİ, F. A. (2010). "Uluslararas1 Muhasebe Eğitimi Literatüründen Bir Kesit: 1997-2008 Dönemi”. Ege Üniversitesi İİBF Ege Akademik Bakış Dergisi, 10(3):885-910.

http://dergi.mumeyek.org/arsivler.php (ET:10.06.2016).

http://sempozyum.mumeyek.org/ (ET: 15.06.2016). 